\title{
Review
}

Clinical

nephron

Practice

Published online: November 22, 2014

DOI: 10.1159/000368589

\section{Rituximab in Primary Membranous Nephropathy: First-Line Therapy, Why Not?}

\author{
Paolo Cravedi $^{a}$ Giuseppe Remuzzi ${ }^{b, c}$ Piero Ruggenenti ${ }^{b, c}$

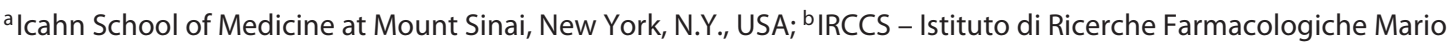 \\ Negri, Clinical Research Center for Rare Diseases 'Aldo e Cele Daccò', and 'Unit of Nephrology, Azienda Ospedaliera \\ Papa Giovanni XXIII, Bergamo, Italy
}

\section{Key Words}

Membranous nephropathy · Nephrotic syndrome ·

Proteinuria $\cdot$ Remission · Rituximab

\begin{abstract}
The ideal treatment of patients with primary membranous nephropathy (MN) and persistent nephrotic syndrome (NS) is still a matter of debate. This is a major issue since these patients may progress to end-stage kidney disease (ESKD) in 5-10 years. Steroids, alkylating agents, and calcineurin inhibitors have been suggested to achieve NS remission and prevent ESKD in this population. Treatment benefits, however, are uncertain and are often offset by serious adverse events (SAEs). Evidence that B cells play a crucial role in the pathogenesis of the disease, both as precursors of autoantibody-producing cells and as antigen-presenting cells, provided the background for explorative studies testing the role of B cell-depletion therapy with the monoclonal antibody rituximab. This approach aimed at selectively inhibiting disease mechanisms without the devastating consequences of unspecific immunosuppression. Finding that rituximab safely ameliorated NS in 8 patients with primary MN fueled a series of observational studies that uniformly confirmed the safety/efficacy profile of rituximab in this context. Although head-to-head comparisons in randomized clinical trials are missing, comparative analyses between series of homoge-
\end{abstract}

neous patient cohorts clearly show at least similar efficacy of rituximab as compared to steroid plus alkylating agents. Moreover, data confirm the dramatically superior safety profile of rituximab that actually appears to be associated with a rate of SAEs even lower than that observed with conservative therapy. Rituximab is also effective in patients resistant to other treatments and its cost-effectiveness is further increased when treatment is titrated to circulating B cells. Recently identified pathogenic antibodies against the $M$ type phospholipase $A_{2}$ receptor will likely provide a novel tool to monitor disease activity and drive rituximab therapy, at least in a subset of patients. Newly developed anti-CD20 antibodies could represent a valuable option for those who fail rituximab therapy. Steroids, alkylating agents, and calcineurin inhibitors should likely be abandoned.

๑) 2014 S. Karger AG, Basel

\section{A Clinical Case}

A 51-year-old patient presents with marked peripheral swelling and a 1-week history of foamy urine. He is not diabetic and his blood pressure is $135 / 90 \mathrm{~mm} \mathrm{Hg}$.

Biologic Treatment in Glomerular Disease

D. Jayne, Cambridge

V. Tesar, Prague

\section{KARGER}

E-Mail karger@karger.com

www.karger.com/nec
(C) 2014 S. Karger AG, Basel

$1660-2110 / 14 / 1284-0261 \$ 39.50 / 0$
Piero Ruggenenti, MD

IRCCS - Istituto di Ricerche Farmacologiche Mario Negri Clinical Research Center for Rare Diseases 'Aldo e Cele Daccò

Via Camozzi 3, IT-24020 Ranica, Bergamo (Italy)

E-Mail pruggenenti@hpg23.it 
Blood and urinary tests show normal creatinine of 1.0 $\mathrm{mg} / \mathrm{dl}$, serum albumin of $2.9 \mathrm{~g} / \mathrm{dl}$, and proteinuria of 9.3 $\mathrm{g} /$ day. A renal biopsy shows diffuse thickening of the glomerular capillary basement membrane with basement membrane spikes at silver stain and subepithelial granular IgG deposits at immunofluorescence. All investigations for secondary causes of membranous nephropathy $(\mathrm{MN})$ are negative or normal, and he has circulating antiphospholipase $\mathrm{A}_{2}$ receptor $\left(\mathrm{PLA}_{2} \mathrm{R}\right)$ antibodies.

$\mathrm{He}$ is started on conservative treatment including angiotensin-converting enzyme (ACE) inhibitors, a low-sodium diet, and diuretics. His symptoms improve, but during the following 3 months his proteinuria does not change and his albumin further declines to $2.5 \mathrm{~g} / \mathrm{dl}$. Despite up-titration of the ACE inhibitor therapy and addon treatment with an angiotensin II receptor blocker (ARB), his proteinuria remains above $9 \mathrm{~g} / 24 \mathrm{~h}$ and his creatinine level is now $1.3 \mathrm{mg} / \mathrm{dl}$. What is the best treatment strategy for this patient?

\section{The Clinical Problem}

Primary MN, the leading cause of nephrotic syndrome (NS) in Caucasian adults, is an immune-mediated disease characterized by deposits of IgG and complement components on the subepithelial layer of the glomerular capillary wall that result in thickening of the glomerular basement membrane, complement activation, and glomerular capillary injury with consequent proteinuria [1]. About $30-40 \%$ of affected patients progress to end-stage kidney disease (ESKD) 5-10 years after diagnosis, whereas about one third have spontaneous remission, normally within 1 or 2 years from disease onset, and another third will have persistent proteinuria with relatively stable renal function [2]. Treatment with steroids and other immunosuppressants including alkylating agents and calcineurin inhibitors has been suggested for patients with persistent NS [3]. However, all of the above medications are burdened by a substantial toxicity with an excess risk of serious adverse events (SAEs) like opportunistic infections, lymphoproliferative disorders, and cancer, which may manifest even decades after patient exposure, and are therefore seldom captured in the timeframe of clinical trials [4].

Results of a comprehensive review of 1,762 patients from 36 randomized controlled trials (RCTs) failed to provide a conclusive indication to immunosuppressive therapy in this context [5]. In four RCTs, corticosteroids combined with alkylating agents significantly increased the rates of complete and partial remission, but led to more adverse events than conservative therapy alone [69]. Cyclophosphamide was safer than chlorambucil, but resulted in more withdrawals or hospitalizations than conservative therapy $[5,10]$. No treatment benefits, instead only side effects, were observed with cyclosporine [5]. Consistently, a large RCT from the UK [11] provided evidence that steroids plus chlorambucil slow renal function loss compared with supportive therapy alone in patients with MN. However, the follow-up was too short to evaluate whether the treatment effect translated into long-term protection against ESKD. Moreover, combination therapy had twice as many SAEs as conservative therapy alone [12]. The event rate exceeded the rate reported in previous RCTs $[7,10,13]$, possibly because of incomplete recording of events in clinical studies before 1996, when the guidelines for SAE reporting were established [14]. Thus, whether benefits in terms of slower renal function loss justify the excess risk of SAEs associated with steroid and alkylating agent combination therapy remained unaddressed [12].

Again, cyclosporine offered no benefit compared with conservative therapy and was associated with remarkably more SAEs. With this background, the recently published Kidney Disease Improving Global Outcomes (KDIGO) guidelines restricted the indication to treatment with alkylating agents to patients at high risk of progression because of persistent NS [15]. The rationale is that in these patients the risks of treatment would be counterbalanced by the reduced risk of kidney failure.

A recent, long-term, single center, cohort study showed that this approach allowed protection from unnecessary treatment exposure in 130 out of 254 patients (51\%) with primary $\mathrm{MN}$ [16]. Over a 10-year observation period, the proportion of remissions was similar among patients given immunosuppressive therapy or conservative therapy alone, even though those on conservative therapy admittedly had a less severe disease to start with. However, the rate of SAEs was remarkably higher in immunosuppressed patients. Particularly, 14 of the 91 patients given cyclophosphamide (15\%) were affected by a malignancy compared to only 4 of the 130 on conservative therapy (3\%). This difference was significant, and in 8 patients the malignancy was fatal. Moreover, those on cyclophosphamide also had a large excess of hospitalizations, infections, bone marrow and liver toxicity, and even cardiovascular and thrombotic events (table 1). Thus, even when immunosuppression is restricted to subjects at increased risk of progression, short- and long-term SAEs remain an important issue. 
Table 1. Main baseline characteristics and adverse events or complications observed in patients with primary MN and NS treated with steroids plus cyclophosphamide [16], rituximab monotherapy [26], or conservative therapy only [16]

\begin{tabular}{lccc}
\hline & $\begin{array}{l}\text { Steroids plus } \\
\text { cyclophosphamide } \\
(\mathrm{n}=91)^{*}\end{array}$ & $\begin{array}{l}\text { Rituximab } \\
\text { monotherapy } \\
(\mathrm{n}=100)^{* *}\end{array}$ & $\begin{array}{c}\text { Conservative } \\
\text { treatment } \\
(\mathrm{n}=130)^{*}\end{array}$ \\
\hline Men & $69(76)$ & $72(72)$ & $79(61)$ \\
Age, years & $56 \pm 13$ & $51.5 \pm 5.9$ & $51 \pm 14$ \\
Serum creatinine, mg/dl & $1.2(1.0-1.6)$ & $1.2(1.0-1.7)$ & $1.0(0.8-1.1)$ \\
P/C, g/10 mmol & $10.4(7.1-15.2)$ & $9.1(5.8-12.8)^{1}$ & $5.1(3.2-7.7)$ \\
SAEs & $35(38)$ & $11(11)$ & $12(9)$ \\
$\quad$ Leukopenia & $35(38)$ & 0 & $2(2)$ \\
Thrombocytopenia & $7(8)$ & 0 & 0 \\
Liver toxicity & $7(8)$ & 0 & 0 \\
Hyperglycemia & $10(11)$ & 0 & $1(1)$ \\
Infection & $30(33)$ & 0 & $1(1)$ \\
Hematuria/cystitis & $1(1)$ & $8(8)$ & 0 \\
Cardiovascular/thrombotic events & $18(20)$ & $3(3)$ & $4(6)$ \\
Malignancy & $14(15)$ & & $4(3)$
\end{tabular}

Data represent $\mathrm{n}(\%)$, means $\pm \mathrm{SD}$, or medians (range). ${ }^{1}$ Expressed as g/24 h. * Median follow-up: 57 months. ** Median follow-up: 29 months.

At the individual patient level, the major challenge to the nephrologist is to carefully weigh the potential benefits of treatment, if any, versus the often devastating consequences of steroids and alkylating agents. When these medications are considered as a possible therapeutic option, a conservative attitude based on the use of antiproteinuric agents such as ACE inhibitors and ARBs and symptomatic therapy of NS [17] remains probably the safer approach in most cases.

\section{Rituximab}

Largely before anti-PLA ${ }_{2} \mathrm{R}$ autoantibodies were found to play a central role in the pathogenesis of approximately $70 \%$ of cases of primary MN [18], data from studies in animals had already consistently shown that antibody production by autoreactive $B$ cell clones initiate the events resulting in injury to the glomerular filtering barrier and consequent proteinuria [19]. These suggested that agents capable of selectively depleting B cells and therefore preventing the production of nephritogenic autoantibodies could ameliorate NS and even resolve the glomerular pathology of primary MN. Availability of a monoclonal antibody against the cell surface antigen CD20 of B cells [20] allowed the exploration of whether specific $\mathrm{B}$ cell inhibition helps improve the outcome of patients with $\mathrm{MN}$ and avoid the side effects of steroids and immunosuppressants. Thus, the anti-CD20 monoclonal antibody rituximab was tested in 8 patients with primary $\mathrm{MN}$ and longlasting persistent proteinuria [21].

Treatment achieved a $60 \%$ reduction in urinary proteins with amelioration of NS in all cases and notably modest side effects with no SAEs [21]. Proteinuria reduction was sustained over 1 year and was associated with stable kidney function and a reduction in body weight, blood pressure, and serum cholesterol [22]. Since this initial experience, other groups have consistently reported the efficacy of rituximab in reducing proteinuria in patients with MN [23-25]. In 2012, a single-center cohort study found that $\mathrm{B}$ cell depletion achieved remission of NS in 65 out of 100 patients and more than $50 \%$ proteinuria reduction in an additional 20 patients [26]. The median duration of proteinuria before rituximab administration was over 2 years (5 years in those previously exposed to other immunosuppressive regimens) and all the patients were on ACE inhibitors or ARBs for at least 6 months, which makes the possibility of spontaneous remissions unlikely. Treatment effect was time dependent and all patients with at least 4 years of follow-up achieved complete or partial remission.

Recent data that anti-PLA ${ }_{2} \mathrm{R}$ antibody titer reduction preceded NS remission in 17 rituximab-treated patients with primary $\mathrm{MN}$ provided convincing evidence of a causal relationship between inhibited B cell antibody pro- 


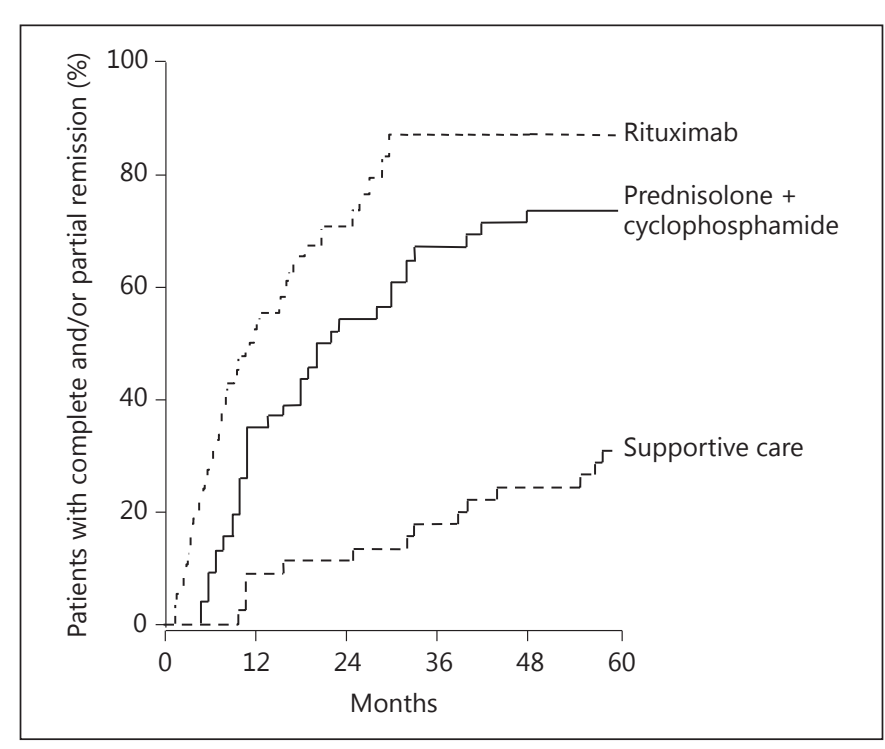

Fig. 1. Kaplan-Meier curves for the percentages of subjects with primary $\mathrm{MN}$ achieving complete remission, partial remission, or both in 100 patients treated with rituximab [26], and in two cohorts of patients given combination treatment with methylprednisolone and cyclophosphamide, and in the corresponding cohort of controls given supportive therapy alone $[7,8]$.

duction and subsequent remission of proteinuria [27]. Actually, finding that reduction of proteinuria up to complete remission may follow B cell depletion by several months is consistent with data in active Heymann nephritis showing that proteinuria reduction after B cell depletion is a slow and progressive phenomenon that may be observed over extended periods of time after glomerular antibody deposition and in situ immune deposit formation have exhausted [28].

Independent of involved mechanisms, comparative outcome analyses of patients with similar baseline characteristics but given different treatment regimens, such as rituximab monotherapy, steroid plus alkylating agents combination therapy, or conservative therapy alone, showed that rituximab-treated patients had a higher rate of remissions (fig. 1) and were more effectively protected from renal function loss (fig. 2) than those treated with steroid and alkylating agents. Those on conservative therapy had the lowest rates of remission and the fastest progression among the three groups, but on the other hand were protected from the side effects of dual immunosuppression. Moreover, a matched cohort study showed that rituximab may safely and persistently reduce proteinuria in patients naive to previous treatments as well as in patients who had previously failed steroids, alkylating agents,

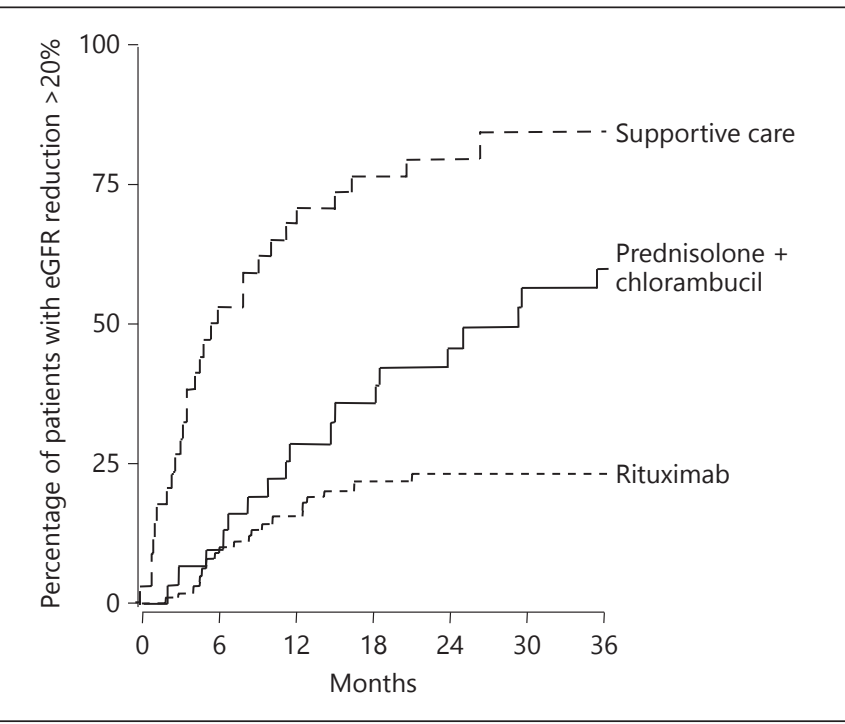

Fig. 2. Kaplan-Meier curves for the percentages of subjects with primary MN achieving $>20 \%$ reduction of eGFR from study enrolment in 100 patients treated with rituximab [26], in the prednisolone + chlorambucil, and in the support therapy cohort [16].

or calcineurin inhibitors, or who had relapsed after transient remission [29]. Among 100 patients with $\mathrm{MN}$ and NS [26], similar remission rates were observed following rituximab first-line or rescue therapy, respectively. Consistently, Segarra et al. [30] showed that rituximab enabled successful withdrawal of tacrolimus or cyclosporine in 13 calcineurin inhibitor-dependent MN patients. Three patients relapsed (mean follow-up: 35 months), but were successfully retreated with a second course of rituximab.

Altogether, the above data converge to indicate that selective B cell depletion by rituximab is at least as effective as other unspecific immunosuppressive treatments in promoting disease remission in MN patients with severe and persistent NS, and can achieve remission even after other treatments have failed. Importantly, clinical benefits were associated with amelioration or even regression of the histologic lesions characteristic of $\mathrm{MN}$, an effect never reported with other medications [31]. Amelioration of clinical signs and histological changes was paralleled by decreased glomerular IgG4 and C3 staining, reabsorption of electron-dense subepithelial deposits, and an increased number of slit diaphragms and percentages of those with electron-dense diaphragms. These findings combined with data that the increase in electrondense diaphragms correlated with the decrease in albu- 
min fractional clearance provided definite evidence that rituximab therapy actually interferes with key mechanisms of the disease [31].

\section{Safety}

Rituximab treatment in autoimmune diseases is generally well tolerated. Five RCTs found that patients treated with rituximab [32-36] had an incidence of severe infections (10\%) very similar to that observed in patients receiving placebo (12\%). Amongst the millions of patients treated with rituximab so far, cases of progressive multifocal leukoencephalopathy (PML) have been described only in patients who received rituximab as a component of multidrug immunosuppressive regimens [37]. Thus, rituximab could be identified in any of these cases as the primary cause of PML. Actually, evidence that PML has a similar incidence also in patients immunosuppressed with rituximab-free regimens strongly suggests that rituximab has a marginal role (if any) in the pathogenesis of this complication as compared to other immunosuppressive medications. Consistently, PML has never been reported in rituximab-treated patients never exposed to other immunosuppressants.

Concomitant and previous exposure to other immunosuppressants most likely had a central role also in the case of a child with steroid-dependent idiopathic NS who developed fulminant enterovirus myocarditis requiring heart transplantation at 13 months after rituximab therapy [38]. Actually, finding that JCV and BK virus (BKV) replication in blood, serum, and urine samples was not affected by rituximab therapy in children with recurrent idiopathic NS [39] provides additional evidence that the facilitating effect of rituximab on complications related to viral reactivations (if any) should not exceed that of other unspecific immunosuppressants.

Consistently, a recent RCT in children with frequently relapsing NS [40] showed no significant increase in SAEs in the rituximab arm over placebo. In particular, the incidence of infections was comparable between the two groups and, as previously reported [41], the reduction in maintenance steroid doses in rituximab-treated patients translated into improved growth and other major clinical benefits. The risk of infections and other complications can even be reduced when rituximab is used to taper down other immunosuppressants in autoimmune diseases, such as in steroid-dependent or frequently relapsing NS [41].

In the specific context of primary $\mathrm{MN}$, the only side effects that can be surely ascribed to rituximab include infusion-related events such as mild hypotension, cutaneous rash, and bronchial wheezing; these are nonserious in nature and patients can usually recover with just temporary interruption of the infusion or in exceptional cases with hydrocortisone [26]. Premedication with $10 \mathrm{mg}$ of chlorphenamine and $500 \mathrm{mg}$ of hydrocortisone may further minimize these events (table 1). SAEs following rituximab exposure are rare. In fact, the number of SAEs in 100 patients treated with rituximab was even lower than in the supportive therapy group from the UK trial (11 vs. $42 \%$ over 29 and 36 months of follow-up, respectively). Moreover, finding that events clustered in the subgroup of patients who failed to achieve remission strongly suggests that they were related to the underlying disease rather than to treatment. Consistently, infectious and cardiovascular events were even reduced in those achieving remission [26].

As for previous trials of steroid and alkylating agents $[7,10,13]$, it cannot be definitely excluded that the risk of late adverse events is underestimated because SAEs such as acute myeloid leukemia, bladder and skin cancer, and other neoplasias may occur as late as 10-20 years after treatment exposure and therefore are not captured during the observation period [4]. However, data in patients with autoimmune diseases or lymphoproliferative disorders exposed to extremely higher doses than the ones used to treat $\mathrm{MN}$, or receiving long-life rituximab therapy for chronic lymphomas, consistently show that rituximab is remarkably safe, particularly compared with other immunosuppressants, over $\geq 10$ years [42-44].

Consistently, 3 cases of cancer observed over a median follow-up of 29 months in 100 consecutive MN patients treated with rituximab [26] reflect the age-adjusted incidence of neoplastic disease in the general population [45]. Of note, the patient who eventually died of lung cancer had been previously exposed to steroids and cyclophosphamide.

This data contrasts with evidence that combined steroid-cyclophosphamide therapy in MN results in a threefold increase in cancer risk over the general population [46]. For the average patient, this finding translates into an increase in annual risk from approximately 0.3 to $1.0 \%$. More generally, comparative analyses between patients treated with rituximab [26] and steroids plus cyclophosphamide [16] have shown a dramatic excess of any considered SAE with dual immunosuppression as compared to rituximab monotherapy, which has actually shown a safety profile similar to that of conservative therapy (table 1). Therefore, within the limitations of comparisons across different studies, rituximab appears to be at least as effective as other unspecific treatments, but is significantly safer. Severe complications such as PML, 
Fig. 3. Circulating B cell number (left panel) and proteinuria (right panel) before and after treatment with a standard four-dose (375 mg/m² each; open circles) or B celldepleting (full circles) rituximab regimen [55].

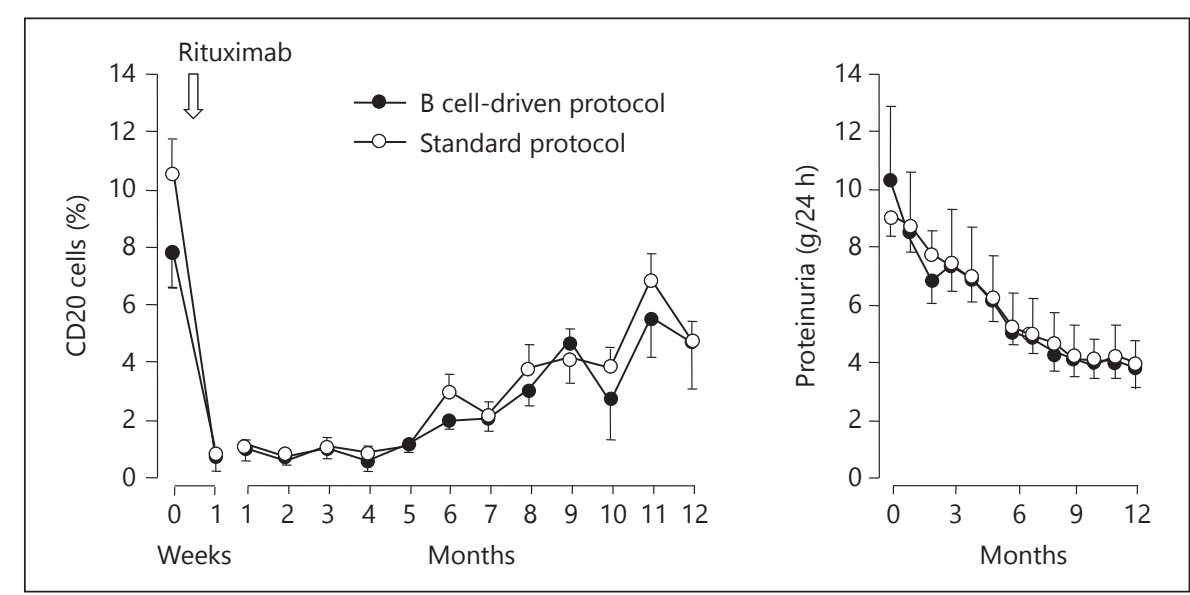

Pneumocystis pneumonia, and even pulmonary fibrosis, which have been superficially ascribed to rituximab [47], have been invariably observed in immunodepressed patients with bone marrow transplantation [48], lymphoproliferative disorders [49], or autoimmune disease who had been exposed to many other immunosuppressants [50]. To the best of our knowledge, none of the events above has ever been reported in subjects exposed to rituximab monotherapy, including MN patients. Actually, observational evidence is available that, by allowing withdrawal of steroid and other immunosuppressants, rituximab may even favor remission of some of the above complications, including PML [Gentile, unpubl. data].

Additionally, an important, but frequently neglected benefit of rituximab therapy is its major impact on patient quality of life [61]. Indeed, due to its excellent safety profile, rituximab per se does not affect to any appreciable extent patient well-being, and at the same time allows the patient to fully benefit from symptom improvements associated with proteinuria reduction and progressive tapering and withdrawal of previous immunosuppressive medications. This contrasts with the experience of patients treated with steroids, alkylating agents, or calcineurin inhibitors who, even when proteinuria remission is achieved, continue to be afflicted by the often invalidating toxicities of these medications [61].

\section{Optimal Dosing}

Dosing of therapeutic monoclonal antibodies is often based on body size, with the perception that body sizebased dosing would reduce intersubject variability in drug exposure [51]. Rituximab has been approved for the treatment of non-Hodgkin's lymphoma, chronic lymphocytic leukemia, rheumatoid arthritis, granulomatosis with polyangiitis, and microscopic polyangiitis with dosing regimens varying from $1 \mathrm{~g} 15$ days apart to multiple cycles of four $375-\mathrm{mg} / \mathrm{m}^{2}$ weekly doses [52]. However, as in the case of most monoclonals, rituximab is target specific (B cells) and has a relatively large therapeutic window and a small contribution of body size to pharmacokinetic variability. Therefore, the dosing paradigm for rituximab should be assessed in the context of these unique characteristics.

Treatment protocols for MN patients vary widely amongst different centers. Some authors used four 375$\mathrm{mg} / \mathrm{m}^{2}$ weekly doses, others preferred an eight-dose 'prolonged protocol' or an 'extended protocol' in which the standard four weekly infusions were followed by two or three monthly infusions [52]. Interestingly, serial measurements of circulating B cells showed that in patients with $\mathrm{MN}$ or lupus, CD20 cells were fully depleted from the circulation just after the first drug administration [53, 54]. This led to question whether further rituximab doses confer additional benefit or, rather, may just increase the risk of adverse reactions or sensitization.

To address this issue, a prospective, matched-cohort study compared the safety/efficacy profile of a B cell-driven rituximab treatment with the standard four $375-\mathrm{mg} / \mathrm{m}^{2}$ dose protocol in $36 \mathrm{MN}$ patients with long-lasting nephrotic range proteinuria refractory to conventional therapy [55]. Patients allocated to the B cell-driven protocol received a second infusion only if they had more than five B cells $/ \mathrm{mm}^{3}$ of peripheral blood after the first rituximab administration, which occurred in only 1 of the 12 patients in this group [55]. Prompt and persistent B cell depletion was achieved in all patients. Time-dependent changes in proteinuria and the other components of NS were similar in the two groups (fig. 3). However, the 
B cell-driven approach was associated with fewer adverse events and less hospitalizations, and was fourfold less expensive, allowing for savings of more than EUR 10,000 (approx. USD 13,000) per patient [55]. Thus, B cell titrated dosing, in addition to improving the risk/benefit profile of the drug, may facilitate access to rituximab even in resource-limited settings.

Indeed, the cost of rituximab is generally regarded as a limitation of this treatment. Independent of treatment benefits that in any cost-effectiveness analyses are prioritized to pure treatment costs, one $375-\mathrm{mg} / \mathrm{m}^{2}$ dose of rituximab in an average 70 -kg patient costs EUR 3,100 (USD 4,130). A 6-month alternate treatment with intravenous plus oral steroids and oral cyclophosphamide at currently recommended doses costs approximately EUR 450 (USD 600). Six-month treatment with cyclosporine A or mycophenolate mofetil would be much more expensive. Considering that 1-day hospitalization in a nonintensive care unit costs EUR 300-500 (USD 400666 ), just one admission because of a treatment-related adverse event would largely offset the costs saved with steroids plus alkylating agents versus rituximab therapy.

\section{Conclusions}

Available data allows to definitely conclude that rituximab is remarkably safer and better tolerated than steroids and alkylating agents for the treatment of primary MN (table 1). Despite the lack of direct head-to-head comparisons in the context of RCTs, several reports from different groups have consistently shown that rituximab achieves remission in approximately $70 \%$ of patients with primary $\mathrm{MN}$, an effect that is similar to that reported for combination therapy with steroid and alkylating agents [23]. Calcineurin inhibitors are not an issue because they are both unsafe and ineffective [11]. Thus, stringent safety considerations can be advocated to recommend the use of rituximab as the first-line therapy for patients at risk of progression because of persistent NS despite conservative therapy with ACE inhibitors and ARBs. Should rituximab therapy fail, the nephrologist would be faced with the dilemma of exposing his patient to toxic medications or observe him to relentlessly progress while on conservative therapy. However, recent availability for clinical use of second- and third-generation anti-CD20 monoclonal antibodies such as obinutuzumab and ofatumumab, which have proven effective for the treatment of B cell lymphomas [56], might open the perspective of a third therapeutic option. A provocative report showed that ofatumumab reduced proteinuria in 5 children with NS resistant to rituximab therapy [57]. Ofatumumab is a fully human monoclonal antibody targeting a unique epitope on CD20 that leads to increased binding affinity to CD20 and a prolonged dissociation rate [58]. The more effective clearance of $\mathrm{B}$ cells expressing low CD20 levels obtained with this antibody may allow depletion of residual autoreactive $B$ cells resistant to rituximab therapy. Due to its excellent safety profile [59], ofatumumab could be taken into consideration instead of blunt and toxic instruments, like nonspecific immunosuppressive agents, which will eventually become a treatment of the past [60].

Thus, pending results from ongoing RCTs comparing rituximab versus placebo (NCT01508468) and immunosuppressive agents (NCT01180036), we suggest to treat the case presented in this initial vignette with a single $375-\mathrm{mg} / \mathrm{m}^{2}$ dose of rituximab, to be repeated only in case the number of circulating B cells at 1 week after rituximab administration is higher than $5 / \mathrm{mm}^{3}$. In addition to proteinuria, anti- $\mathrm{PLA}_{2} \mathrm{R}$ antibodies should be measured before treatment, and at regular intervals thereafter to monitor disease activity and to drive repeated treatments in case of antibody increase after initial reduction [Ruggenenti et al., unpubl. data]. In case of treatment failure, exposure to other toxic treatments should probably be avoided. Should the patient be a potential candidate for kidney transplantation, this waiting attitude would be instrumental to avoid the risk of add-on, adverse interactions between overzealous immunosuppression and subsequent antirejection treatment.

References 
5 Chen Y, Schieppati A, Cai G, Chen X, Zamora J, Giuliano GA, et al: Immunosuppression for membranous nephropathy: a systematic review and meta-analysis of 36 clinical trials. Clin J Am Soc Nephrol 2013;8:787-796.

6 Braun N, Erley C, Benda N, Zauner I, Kanis $\mathrm{R}$, Grupp C, et al: Therapy of membranous glomerulonephritis with nephrotic syndrome. 5 years follow-up of a prospective, randomised multi-centre study. Nephrol Dial Transplant 1995;10:967.

7 Jha V, Ganguli A, Saha TK, Kohli HS, Sud K, 20 Gupta KL, et al: A randomized, controlled trial of steroids and cyclophosphamide in adults with nephrotic syndrome caused by idiopathic membranous nephropathy. J Am Soc Nephrol 2007;18:1899-1904.

8 Ponticelli C, Zucchelli P, Passerini P, Cesana B, Locatelli F, Pasquali S, et al: A 10-year follow-up of a randomized study with methylprednisolone and chlorambucil in membranous nephropathy. Kidney Int 1995;48:16001604.

-9 Kosmadakis G, Filiopoulos V, Smirloglou D, Skarlas P, Georgoulias C, Michail S: Comparison of immunosuppressive therapeutic regimens in patients with nephrotic syndrome due to idiopathic membranous nephropathy. Renal Fail 2010;32:566-571.

10 Ponticelli C, Altieri P, Scolari F, Passerini P, Roccatello D, Cesana B, et al: A randomized study comparing methylprednisolone plus chlorambucil versus methylprednisolone plus cyclophosphamide in idiopathic membranous nephropathy. J Am Soc Nephrol 1998;9:444-450.

$\checkmark 11$ Howman A, Chapman TL, Langdon MM, Ferguson C, Adu D, Feehally J, et al: Immunosuppression for progressive membranous nephropathy: a UK randomised controlled trial. Lancet 2013;381:744-751.

12 Ruggenenti P, Remuzzi G: Idiopathic membranous nephropathy: back to the future? Lancet 2013;381:706-708.

13 Ponticelli C, Zucchelli P, Passerini P, Cagnoli L, Cesana B, Pozzi C, et al: A randomized trial of methylprednisolone and chlorambucil in idiopathic membranous nephropathy. N Engl J Med 1989;320:8-13.

14 International Conference on Harmonisation of Technical Requirements for Registration of Pharmaceuticals for Human Use. Guideline for Good Clinical Practice E6(R1). http:// wwwichorg/fileadmin/Public_Web_Site/ ICH_Products/Guidelines/Efficacy/E6_R1/ Step4/E6_R1_Guidelinepdf (June 10, 1996) (accessed on August 1, 2014).

15 Chapter 7: ldiopathic membranous nephropathy. Kidney Int Suppl (2011) 2012;2:186197.

16 van den Brand JA, van Dijk PR, Hofstra JM, Wetzels JF: Long-term outcomes in idiopathic membranous nephropathy using a restrictive treatment strategy. J Am Soc Nephrol 2014;25:150-158.

17 Remuzzi A, Schieppati A, Battaglia C, Remuzzi G: Angiotensin-converting enzyme in- hibition ameliorates the defect in glomerular size selectivity in hyponatremic hypertensive syndrome. Am J Kidney Dis 1989;14:170-177. 18 Beck LH Jr, Bonegio RG, Lambeau G, Beck DM, Powell DW, Cummins TD, et al: M-type phospholipase $\mathrm{A}_{2}$ receptor as target antigen in idiopathic membranous nephropathy. N Engl J Med 2009;361:11-21.

19 Debiec H, Ronco P: Immunopathogenesis of membranous nephropathy: an update. Semin Immunopathol 2014;36:381-397.

20 Pescovitz MD: Rituximab, an anti-CD20 monoclonal antibody: history and mechanism of action. Am J Transplant 2006;6:859866.

21 Remuzzi G, Chiurchiu C, Abbate M, Brusegan V, Bontempelli M, Ruggenenti P: Rituximab for idiopathic membranous nephropathy. Lancet 2002;360:923-924.

22 Ruggenenti P, Chiurchiu C, Brusegan V, Abbate M, Perna A, Filippi C, et al: Rituximab in idiopathic membranous nephropathy: a oneyear prospective study. J Am Soc Nephrol 2003;14:1851-1857.

23 Bomback AS, Derebail VK, McGregor JG, Kshirsagar AV, Falk RJ, Nachman PH: Rituximab therapy for membranous nephropathy: a systematic review. Clin J Am Soc Nephrol 2009;4:734-744.

24 Fervenza FC, Abraham RS, Erickson SB, Irazabal MV, Eirin A, Specks U, et al: Rituximab therapy in idiopathic membranous nephropathy: a 2-year study. Clin J Am Soc Nephrol 2010;5:2188-2198.

25 Fervenza FC, Cosio FG, Erickson SB, Specks U, Herzenberg AM, Dillon JJ, et al: Rituximab treatment of idiopathic membranous nephropathy. Kidney Int 2008;73:117-125.

26 Ruggenenti P, Cravedi P, Chianca A, Perna A, Ruggiero B, Gaspari F, et al: Rituximab in idiopathic membranous nephropathy. J Am Soc Nephrol 2012;23:1416-1425

27 Beck L, Fervenza F, Beck D, Bonegio R, Erickson $\mathrm{SB}$, Cosio FG, et al: Anti-PLA ${ }_{2} \mathrm{R}$ autoantibodies and response to rituximab treatment in membranous nephropathy. J Am Soc Nephrol 2011;22:1543-1550.

28 Makker SP, Kanalas JJ: Course of transplanted Heymann nephritis kidney in normal host. Implications for mechanism of proteinuria in membranous glomerulonephropathy. J Immunol 1989;142:3406-3410.

29 Cravedi P, Sghirlanzoni MC, Marasa M, Salerno A, Remuzzi G, Ruggenenti P: Efficacy and safety of rituximab second-line therapy for membranous nephropathy: a prospective, matched-cohort study. Am J Nephrol 2011; 33:461-468.

30 Segarra A, Praga M, Ramos N, Polanco N, Cargol I, Gutierrez-Solis E, et al: Successful treatment of membranous glomerulonephritis with rituximab in calcineurin inhibitordependent patients. Clin J Am Soc Nephrol 2009;4:1083-1088.

-31 Ruggenenti P, Cravedi P, Sghirlanzoni MC, Gagliardini E, Conti S, Gaspari F, et al: Effects of rituximab on morphofunctional abnor- malities of membranous glomerulopathy. Clin J Am Soc Nephrol 2008;3:1652-1659.

-32 Meijer JM, Meiners PM, Vissink A, Spijkervet FK, Abdulahad W, Kamminga N, et al: Effectiveness of rituximab treatment in primary Sjogren's syndrome: a randomized, doubleblind, placebo-controlled trial. Arthritis Rheum 2010;62:960-968.

33 Dass S, Bowman SJ, Vital EM, Ikeda K, Pease CT, Hamburger J, et al: Reduction of fatigue in Sjogren syndrome with rituximab: results of a randomised, double-blind, placebo-controlled pilot study. Ann Rheum Dis 2008;67: 1541-1544.

- 34 Merrill JT, Neuwelt CM, Wallace DJ, Shanahan JC, Latinis KM, Oates JC, et al: Efficacy and safety of rituximab in moderately-to-severely active systemic lupus erythematosus: the randomized, double-blind, phase II/III systemic lupus erythematosus evaluation of rituximab trial. Arthritis Rheum 2010;62: 222-233.

- 35 Stone JH, Merkel PA, Spiera R, Seo P, Langford CA, Hoffman GS, et al: Rituximab versus cyclophosphamide for ANCA-associated vasculitis. N Engl J Med 2010;363:221-232.

- 36 Jones RB, Tervaert JW, Hauser T, Luqmani R, Morgan MD, Peh CA, et al: Rituximab versus cyclophosphamide in ANCA-associated renal vasculitis. N Engl J Med 2010;363:211220.

37 Carson KR, Evens AM, Richey EA, Habermann TM, Focosi D, Seymour JF, et al: Progressive multifocal leukoencephalopathy after rituximab therapy in HIV-negative patients: a report of 57 cases from the Research on Adverse Drug Events and Reports project. Blood 2009;113:4834-4840.

38 Sellier-Leclerc AL, Belli E, Guerin V, Dorfmuller P, Deschenes G: Fulminant viral myocarditis after rituximab therapy in pediatric nephrotic syndrome. Pediatr Nephrol 2013; 28:1875-1879.

39 Delbue S, Ferraresso M, Elia F, Belingheri M, Carloni C, Signorini L, et al: Investigation of polyomaviruses replication in pediatric patients with nephropathy receiving rituximab. J Med Virol 2012;84:1464-1470.

40 Iijima K, Sako M, Nozu K, Mori R, Tuchida N, Kamei K, et al: Rituximab for childhoodonset, complicated, frequently relapsing nephrotic syndrome or steroid-dependent nephrotic syndrome: a multicentre, doubleblind, randomised, placebo-controlled trial. Lancet 2014, Epub ahead of print.

41 Ruggenenti P, Ruggiero B, Cravedi P, Vivarelli M, Massella L, Marasa M, et al: Rituximab in steroid-dependent or frequently relapsing idiopathic nephrotic syndrome. J Am Soc Nephrol 2014;25:850-863.

42 Gea-Banacloche JC: Rituximab-associated infections. Semin Hematol 2010;47:187-198.

$\checkmark 43$ Lanini S, Molloy AC, Fine PE, Prentice AG, Ippolito G, Kibbler CC: Risk of infection in patients with lymphoma receiving rituximab: systematic review and meta-analysis. BMC Med 2011;9:36. 
-44 Tan CS, Koralnik IJ: Progressive multifocal leukoencephalopathy and other disorders caused by JC virus: clinical features and pathogenesis. Lancet Neurol 2010;9:425-437.

-45 Jemal A, Siegel R, Ward E, Murray T, Xu J, Smigal C, et al: Cancer statistics, 2006. CA Cancer J Clin 2006;56:106-130.

46 van den Brand JA, van Dijk PR, Hofstra JM, Wetzels JF: Cancer risk after cyclophosphamide treatment in idiopathic membranous nephropathy. Clin J Am Soc Nephrol 2014;9: 1066-1073.

47 Feehally J: Targeted therapies: Is there a role for rituximab in nephrotic syndrome? Nat Rev Nephrol 2014;10:245-247.

-48 Kaufman GP, Aksamit AJ, Klein CJ, Yi ES, Delone DR, Litzow MR: Progressive multifocal leukoencephalopathy: a rare infectious complication following allogeneic hematopoietic cell transplantation (HCT). Eur J Haematol 2014;92:83-87.

49 Tavazzi E, Ferrante P, Khalili K: Progressive multifocal leukoencephalopathy: an unexpected complication of modern therapeutic monoclonal antibody therapies. Clin Microbiol Infect 2011;17:1776-1780.
50 Clifford DB, Ances B, Costello C, RosenSchmidt S, Andersson M, Parks D, et al: Rituximab-associated progressive multifocal leukoencephalopathy in rheumatoid arthritis. Arch Neurol 2011;68:1156-1164.

51 Bai S, Jorga K, Xin Y, Jin D, Zheng Y, DamicoBeyer LA, et al: A guide to rational dosing of monoclonal antibodies. Clin Pharmacokinet 2012;51:119-135.

52 Ruggenenti P, Cravedi P, Remuzzi G: Rituximab for membranous nephropathy and immune disease: less might be enough. Nat Clin Pract Nephrol 2009;5:76-77.

53 Gabardi S, Martin ST, Roberts KL, Grafals M: Induction immunosuppressive therapies in renal transplantation. Am J Health Syst Pharm 2011;68:211-218.

54 Pepper R, Griffith M, Kirwan C, Levy J, Taube D, Pusey C, et al: Rituximab is an effective treatment for lupus nephritis and allows a reduction in maintenance steroids. Nephrol Dial Transplant 2009;24:3717-3723.
55 Cravedi P, Ruggenenti P, Sghirlanzoni MC, Remuzzi G: Titrating rituximab to circulating $B$ cells to optimize lymphocytolytic therapy in idiopathic membranous nephropathy. Clin J Am Soc Nephrol 2007;2:932-937.

56 Jain P, O’Brien S: Anti-CD20 monoclonal antibodies in chronic lymphocytic leukemia Expert Opin Biol Ther 2013;13:169-182.

57 Basu B: Ofatumumab for rituximab-resistant nephrotic syndrome. N Engl J Med 2014;370: 1268-1270.

58 Zhang B: Ofatumumab. MAbs 2009;1:326-331.

59 Sorensen PS, Lisby S, Grove R, Derosier F, Shackelford S, Havrdova E, et al: Safety and efficacy of ofatumumab in relapsing-remitting multiple sclerosis: a phase 2 study. Neurology 2014;82:573-581.

60 Glassock RJ: The treatment of idiopathic membranous nephropathy: a dilemma or a conundrum? Am J Kidney Dis 2004;44:562566.

61 Marasà $\mathrm{M}$, Cravedi $\mathrm{P}$, Ruggiero $\mathrm{B}$, Ruggenenti P: Refractory focal segmental glomerulosclerosis in the adult: complete and sustained remissions of two episodes of nephrotic syndrome after a single dose of rituximab. BMJ Case Rep 2014;2014. 